\title{
La educación sexual integral como proyecto de justicia social ${ }^{1}$
}

\author{
Graciela Morgade \\ Universidad Nacional de Buenos Aires, Facultad de Filosofia y Letras, Argentina \\ gamorgade@hotmail.com
}

Una noción central estructura nuestras investigaciones y opera como una potente "clave" introductoria para los temas que nos ocupan: la "construcción social del cuerpo sexuado". Según esta hipótesis, la materialidad se vincula dialécticamente con una cultura, con un momento histórico, con una clase social, en un mundo étnico, en una generación, en un contexto que hace inescindible nuestro cuerpo material de nuestro cuerpo social.

Hay algunos registros más evidentes que otros de esta construcción social de los cuerpos. Los tatuajes, por ejemplo, son intervenciones que combinan una decisión personal con determinaciones económicas, estéticas, culturales. También lospiercings, que se diferencian de los aros porque, en general, hasta hace algunos años, los aros eran intervenciones en los cuerpos de las niñas como un modo de feminizar ese cuerpo recién nacido. ¿Por qué decimos piercing, además de ser una palabra en inglés, y no aros? ¿O por qué las personas que usan aros, las mujeres, o los compañeros varones que usan aros a veces no los reconocen como piercings? Entendemos que es porque, de alguna manera, está integrado a nuestros cuerpos. Este adorno que marcaba una identidad sexo-genérica está integrado y forma parte de esta construcción social que ni siquiera percibimos como una intervención.

Algunos ejemplos más. El botox es una toxina que produce un tipo de bacteria y que se usa en algunos tratamientos médicos para la espasticidad. Usado con un criterio estético para eliminar las arrugas es más caro que ponerse un arito, bastante más caro, y su efecto dura un tiempo y después se va. $\mathrm{O}$ sea, hay que seguir poniéndose botox e invirtiendo dinero.

Otras intervenciones, mucho más complejas y ya prohibidas, son las que se aplicaban, por ejemplo, a las mujeres de Birmania: en esa sociedad, para que fueran consideradas más bellas y apetecibles, se les colocaban aros en los cuellos, que quedaban cada vez más largos (por eso se las llamaba "mujeres cuello de jirafa") y, con el tiempo, esos cuellos no podían no tener los aros porque sus músculos habían perdido la fuerza para sostener el peso de la cabeza. O en algunas comunidades en China, donde las mujeres eran obligadas a usar los zapatos mucho más pequeños que el tamaño de su pie ya que el pie pequeño era considerado bello. Estas intervenciones tuvieron durante siglos una presencia que determinó cánones de belleza y también posiciones económicas en la estructura social.

Ahora bien, cuando observamos cualquier cuerpo femenino, ¿nos preguntamos acerca de las intervenciones sociales que hubo o hay de manera constante sobre ese cuerpo? Posiblemente no lo hacemos. Sin embargo, maquillaje, dietas, depilación, tacos, gimnasio, cirugías y más son intervenciones sociales sobre el cuerpo.

La invitación central desde nuestra perspectiva es a desnaturalizar y desencializar a esos cuerpos. Y también a los cuerpos masculinos. Los cuerpos son intervenidos en un determinado momento histórico, en determinadas relaciones económicas, en un determinado lugar geográfico, en tradiciones, en religiones. Es frecuente pensar el cuerpo de la travesti como un cuerpo construido, pero si volvemos sobre la hipótesis acerca de la construcción social del cuerpo, evidentemente el cuerpo de la travesti es un cuerpo tan construido e intervenido como otros, con una historia y además una identificación de lucha que hace que se construya una identidad que no es ni mujer ni varón. Es decir, el cuerpo travesti trasciende el binarismo. Binarismo 
hoy también discutido por otras identidades, transexuales, transgéneros, que, de alguna manera, también nos devuelven la pregunta sobre nuestra propia identidad trans.

Sin embargo, a pesar de la lucha y la conquista de derechos que han y hemos protagonizado, hay cuerpos que pesan más y cuerpos que pesan menos, que importan más y que importan menos. Y la identidad travesti es una de las identidades sexo-genéricas más condenadas y más rechazadas; pero no es la única.

Existen tres grandes organizaciones estructurales de poder que enmarcan la posición relativa de los cuerpos construidos: el patriarcado heteronormativo homo/lesbo/bitransfóbico, el capitalismo y la colonialidad. El patriarcado -categoría que nos permite entender la dimensión sexuada-, el capitalismo -y el problema de la división social del trabajo y la distribución de la riqueza- y la condición colonial de nuestros países de América Latina, vienen siendo objeto de un análisis en profundidad a partir de la tradición de pensamiento de la decolonialidad que retoma, de alguna manera, una posición que hace mucho tiempo se llamaba "raza". Hoy pensamos la categoría colonialidad articulándola de manera interseccional con el capitalismo y el patriarcado heteronormativohomo/lesbo/transfóbico, y sosteniendo que se trata de un postulado teórico en el que uno de los vectores no puede ser analizado sin pensar en los otros.

En esta intervención, haremos foco en los procesos educativos, fundamentalmente, desde la dimensión del patriarcado. La investigación, que siempre es social y por eso mismo siempre es parcial, nos lleva a colocar la mirada en algunas formas de relación. Sin embargo, estamos pensando en un sistema en que estas tres condiciones están íntimamente conectadas. No podemos hacer una crítica al capitalismo, esto es, a las relaciones de poder económicas, sin pensar en cuerpos sexuados, sin pensar en relaciones coloniales. Tampoco podemos hacer una crítica al patriarcado sin pensar en relaciones económicas y sin pensar en relaciones coloniales, y lo mismo en relación con la colonialidad.

Ahora bien, una de las dimensiones de la educación más evidentes y menos pensadas es el "cuerpo docente". La categoría "cuerpo docente" fue usada, generalmente, como descripción administrativa, y fue problematizada desde la perspectiva de "lo que se enferma". Pero el cuerpo sexuado docente ha sido casi imperceptible. El guardapolvo que hemos usado en la escuela primaria lo ocultó y lo mostró a la vez. Esa mujer vestida de blanco fue convocada a ser docente como una prolongación de un supuesto lugar maternal. También, fue convocada a ser docente en la Argentina para incorporarse al gran proyecto de la educación pública, un proyecto de histórica relevancia social e individual, al que se convoca a mujeres supuestamente maternales, a las que se le podía pagar menos porque iban a depender económicamente del padre o del marido. En esos tiempos, era impensable que una mujer fuera autónoma y, además, tengamos en cuenta que -hacia fines del siglo XIX o principios del siglo XX, en Argentina- el discurso educativo comenzaba a plantear lo que algunos llaman la dulcificación de las relaciones escolares, es decir, un discurso que se pronuncia contra los castigos corporales.

Queremos dejar planteado que se trata de un largo proceso de reapropiación, incompleto aún desde mi perspectiva, de la conducción de ese ejército de reserva que eran las mujeres. Las familias que querían que sus hijas estudiaran, encontraron en la escuela normal una salida para un "trabajo femenino", un lugar de realización personal y económica, y de alguna manera, ello hizo que fuera enormemente exitosa esa empresa. Pocas políticas educativas en la Argentina fueron tan exitosas: abrieron las escuelas normales y se llenaron de mujeres. Cuando hablamos de educación nos estamos refiriendo al cuerpo de mujeres o a un cuerpo feminizado. La enorme presencia de mujeres en todos los niveles de enseñanza confirma esta presunción: en el nivel inicial, la presencia de mujeres es mayoritaria con un 99\%; en el nivel primario, $92 \%$ y en el nivel secundario, el $62 \%$ son mujeres.

La pregunta que queda flotando es cuánto les costó o cuanto nos costó a las maestras y profesoras reconocernos como trabajadoras, reconocer la legitimidad de la militancia gremial y reconocer que -en aquel momento- el discurso de la madre educadora había sido una gran estrategia para encubrir una relación laboral precaria y muy perjudicial para las mujeres. Durante mucho tiempo, las mujeres trabajamos sin contar con derechos laborales que nos asistieran. A esta tarea y en estas precarias condiciones, se convocó a las "dulces 
maestras". O el otro estereotipo, mucho menos vigente en la actualidad, la profesora violenta y amargada. ¿Cuál es el supuesto de la profesora amargada? Que es soltera, ¡solterona!, y, por eso, es malvada. O las maestras infantiles, sobre todo en el nivel inicial del sistema educativo. Esas mujeres son convocadas a las escuelas a trabajar y son tratadas como niñas, y ese halo que encontramos en el jardín de infantes de convertir todo objeto y el espacio mismo en adorno o medio de expresión, hace que las flores y los colores invadan toda la sala incluyendo el cuaderno de comunicaciones entre adultas y adultos. El jardín de infantes es un lugar de fuerte reproducción del supuesto acerca de que las maestras son un poco niñas y que hay que ser un poco niñas para poder vincularse con la infancia.

Sin embargo, hay imágenes más recientes de maestras trabajadoras, y sobre todo maestras que sostienen el Programa de Educación Sexual Integral (ESI) con sus pañuelos verdes. El camino que habilita la ESI conduce al reconocimiento del cuerpo docente desde la perspectiva sexo-genérica. Permite reapropiarnos críticamente de la condición femenina, y también de la condición masculina de muchos compañeros varones que han padecido la homofobia, y aún la padecen.

Se trata, sobre todo, de recuperar la dimensión de la política del afecto y del cuidado; porque, para ser docente, no basta con amar a los niños y a las niñas -que era lo que decían antes: "Yo soy maestra porque me gustan los chicos". No basta, pero si no hay un amor por la infancia, es imposible ser docente y considero que las maestras, les maestres, vienen politizando el trabajo de enseñar, politizando la función del cuidado que implica enseñar, de enseñar cuidando. Creo, políticamente, en el amor en la docencia. Me reconcilié con el amor, pero ya no con el amor romántico, el amor que supone la entrega altruista, el mandato de amar. Es necesario recuperar el sentido político de enseñar y recuperar a las otras mujeres que también están en las escuelas. Esas otras que fueron construidas como opuestas, las madres de la escuela. Ese antiguo antagonismo entre mujeres que hoy está interpelado cuando las madres o las docentes son víctimas de violencia de género. En esos momentos, es posible reconocerse en tanto mujeres y esos cuerpos feminizados se encuentran en una posibilidad política de integrar un sujeto político más complejo.

Todos estos contenidos tienen que ver con la educación sexual y tienen que ver con la reapropiación de los cuerpos docentes desde una perspectiva crítica. Se trata, no solamente de describir, sino también de poder identificar las formas del poder que están subyaciendo a estas formas de construcción. Y aprovecho para citar a una estudiante de un profesorado de nivel inicial, del Instituto Superior de Profesorado de Educación Inicial "Sara Eccleston", comentando que en una marcha en defensa de los institutos de formación docente de la Ciudad Autónoma de Buenos Aires se escuchó cantar "no somos señoritas, ni segundas madres: docentes trabajadoras antipatriarcales".

Para trabajar sobre las prácticas cotidianas contamos con otra hipótesis muy fuerte, por cierto, que sintetiza nuestra posición de cara al sistema educativo. Trabajamos con la premisa "Toda educación es sexual". La pregunta que de ella se desprende es ¿hacia dónde queremos dirigir nuestra educación? Toda educación es sexual porque siempre habla de cuerpos sexuados. Si tenemos que ir a luchar a la calle y de manera táctica, pediremos "ESI, ESI, ESI". Vamos a ir a pedir más educación sexual integral. Pero complejizando nuestra mirada, podemos sostener que la educación es sexuada, tiene que ser sexuada desde la perspectiva de género y en dirección a lograr mayor justicia y emancipación para las mujeres y otrxs grupos oprimidxs. Es decir, como educadorxs debemos hacernos cargo del carácter sexuado de los cuerpos y de que siempre se están tramitando significados sexo-genéricos en todas las prácticas.

El punto de partida en el que nos apoyamos todas las compañeras y les compañeres que luchamos por la educación sexuada fueron sucesivas investigaciones generadas desde los feminismos y en el propio campo de la educación. Por ejemplo, estos trabajos han podido mostrar el carácter androcéntrico de los contenidos escolares, en el campo de la historia, de la lengua y la literatura, la formación ética y ciudadana, etcétera.

Sabemos que -tanto en las áreas centrales de la educación como también en las escuelas y en cada aula- se realiza un recorte, una selección de los saberes a ser transmitidos y trabajados. Sabemos también que quedan por fuera muchas voces. El androcentrismo -que, además, es el androcentrismo blanco y burgués- se vinculada 
claramentecon el origen del conocimiento académico y científico, con los señores que durante siglos estuvieron en las universidades y en las academias controlando qué se investigaba y qué no se investigaba. Porque, pensemos, la Universidad -tal como la conocemos- viene de las escuelas catedralicias y de las escuelas monásticas de la Edad Media europea. En la universidad que tenemos, durante nueve siglos, estuvieron excluidas todas las mujeres y la enorme mayoría de los hombres, también. Pero las mujeres, todas. Entonces, ¿dónde y cómo se construyó el conocimiento de base que es la fuente del curriculum? Hay una enorme tarea que tenemos que hacer y seguir haciendo, que tiene que ver con las universidades, tiene que ver con los centros de investigación, tiene que ver con los equipos técnicos que definen el curriculum escolar, y es una tarea que tenemos hoy que encarar en profundidad. Para ello, es necesario producir una crítica epistemológica de los saberes de base que transmite el sistema escolar y, fundamentalmente, volver la mirada sobre la biología como disciplina porque ha sido históricamente el espacio curricular destinado a la enseñanza de la educación sexual haciendo del profesor o profesora de biología el/la único/a y principal responsable de una clase plagada de sesgos patriarcales, androcéntricos, capitalistas y coloniales.

¿Qué encontramos en lo que en educación llamamos "el curriculum oculto"? Numerosas investigaciones señalan que existen expectativas diferenciales respecto de los chicos y de las chicas. Por ejemplo, el persistente estereotipo de la "alumna prolija". Es notable esta división sexual de las expectativas escolares y esto se repite de manera dramática en las escuelas técnicas, donde hay chicas que eligieron la modalidad y reciben un trato diferencial porque hay una sospecha respecto de su inteligencia o de su capacidad para desempeñarse en un futuro laboral. Y cuando se dice que las mujeres están excluidas de los ámbitos científicos, cuantitativamente es evidente porque todavía sigue habiendo prejuicios sobre la capacidad de las mujeres para desempeñarse en ciertos ámbitos científicos y tecnológicos históricamente vedados. Las mujeres están obligadas a hacer un doble trabajo: por un lado, rendir; y por otro, demostrar que, aunque son mujeres, pueden desempeñarse igual que los varones. No me refiero a las ciencias humanas y a las sociales que son espacios más feminizados, aunque conservan sus jerarquías androcéntricas. Me refiero a los espacios clásicos de las ciencias exactas y de las ingenierías, donde persiste aún hoy un sesgo sexista que dificulta la incorporación de mujeres en igualdad de condiciones. ¿Y de qué estamos hablando? Probablemente, estamos hablando del mercado de trabajo, pero en la vida cotidiana de los espacios educativos todavía se tramitan algunas sospechas.

Y también, lo que encontramos como una especie de gran caldo de cultivo para la ley de ESI son los silencios, aquello de lo que no se ha hablado históricamente y, como silencio sistemático, resulta estridente. Las sexualidades, los sentimientos, el abuso y la violencia, el aborto. Absoluto silencio. Y menos, entonces, los sentimientos y la experiencia como fuente del conocimiento. No me refiero a abordar situaciones personales en un sentido psicoanalítico de intervención clínica o de modos de soluciones cada caso, orientación que por cierto deberá buscarse por fuera del ámbito escolar. Sí sostenemos que es el ámbito escolar el espacio para problematizar la experiencia, porque muchas veces las situaciones de dolor y de padecimiento tienen que ver con situaciones de poder y tienen que ver con opresiones que son sistemáticas y que son estructurales. Es evidente que estamos hablando de la posibilidad de mirar políticamente la experiencia, y eso por supuesto que tiene que ver con la voluntad de transformación.

Y con estos antecedentes, se vota, en 2006, la Ley de Educación Sexual Integral y empieza su camino. ${ }^{2}$ Empieza con la conformación, en 2007, de una comisión que tiene la tarea de brindar los fundamentos pedagógicos de los Lineamientos Curriculares que se votan en el año $2008,{ }^{3}$ cuando también se crea el Programa Nacional.

La organización de la educación en nuestro país es federal, y cuando dentro de una provincia se encuentra una enorme resistencia a la aplicación de una ley como la ESI, se hace muy difícil avanzar sobre los sistemas provinciales. Creo que el estado nacional tiene una fuerza de legitimación que le permitiría poder avanzar en las provincias para hacer que las leyes nacionales se cumplan. Y el Programa Nacional fue de a poco recorriendo un camino en el que se fueron perfilando algunos ejes centrales. 
Si somos coherentes -y nosotras somos coherentes con esta idea de problematizar los cuerpos, de problematizar e historizar la construcción social de los cuerpos- definitivamente no podemos centrar la educación sexual solamente en el estudio anatómico o en la prevención de la transmisión de infecciones o la prevención del embarazo. No puede ser ése el enfoque excluyente. El gobierno nacional actual está intentando volver para atrás con este punto poniendo un énfasis creo, desde mi punto de vista, excesivo. Además, retrasa al colocar el foco casi exclusivamente en la prevención del embarazo en lugar de la sexualidad como derecho. Es por eso que el actual gobierno propone una campaña a cargo del equipo nacional de la ESI sobre el Embarazo No Intencional Adolescente (ENIA). ${ }^{4}$ La educación sexual no puede reducirse a informar a las y los jóvenes sobre los métodos anticonceptivos. No puede ser solo hablar de prevención del embarazo. En cambio, la ESI propone incorporar la dimensión del placer. Los cuerpos se disfrutan, se viven, se conocen, se exploran y son una fuente de placer, forman parte del proceso de subjetivación la sexualidad y la sexuación. Por lo tanto, incorporar la dimensión del placer trata básicamente de contraponerse a la mirada represiva, propia de las religiones. El enfoque de la educación para el amor, el enfoque de la educación sexual llamada educación para el amor, es el enfoque que básicamente construyó el Consejo Nacional de Educación Católica (CONSUDEC): centrado en la abstinencia como método; en la castidad, en la genitalidad, en el ejercicio activo de la genitalidad en el coito dentro del matrimonio y para tener hijxs. Hoy están enseñando en algunas provincias de nuestro país ese enfoque de educación sexual.

Así como no podemos reducir la educación sexual al modelo biomédico, no podemos reducir la educación sexual a un modelo moralizante en base a una lectura religiosa que, en general, propone una visión represiva y vuelve a poner a la sexualidad en el lugar del problema. "Tenemos el problema de que nos podemos infectar", "tenemos el problema de que podemos quedar embarazadas", "tenemos el problema de que nos gusta" ¡ese es un gran problema!-. El enfoque biomédico y el enfoque represivo moralizante no son ESI. Porque la Educación Sexual Integral abarca todas las dimensiones de la sexualidad, historizando desde la perspectiva de género y sosteniendo una ética que es la de los derechos humanos. Hay una direccionalidad política que son los derechos humanos y ellos, básicamente, hacen que nos reconozcamos a nosotros mismos, a nosotras mismas, a nosotres mismes como sujetos de derecho y sujetos de deseo. $\mathrm{Y}$ a las otras personas también como sujetos de derecho y deseo. Si logramos concebirnos y concebir a les otres como sujetos de derecho y deseo, ese es el marco ético de los derechos humanos más potente para construir relaciones saludables, amorosas. Y con amorosas y saludables no estoy diciendo que puede ser la suma de ambos tipos de relación. Puede ser la una o la otra, pero que -en todo caso- ambas relaciones tienen que ver con el cuidado.

Coherente con este desarrollo teórico que propone la ESI, es importante reconceptualizar la mirada acerca de los cuerpos. Entonces, esa mirada binaria, de nena-nene, mujer-varón, ya nos queda estrecha. Ya no podemos pensar en dos cuerpos, dos sexos, dos géneros, porque justamente, lo que muy rápidamente hemos visto pero sabemos, los movimientos socio-sexuales pusieron en juego la visibilización de las identidades sexo- genéricas que, además de respetar, también la ESI busca visibilizar. Y esto, también, forma parte del proyecto educativo de la ESI, no pensar binariamente tiene que ver con respetar y tiene que ver con promover la visibilización, la expresión, la pluriglosia de las experiencias, o sea que se puedan expresar diferentes miradas, diferentes voces, diferentes experiencias.

En todos los niveles educativos, todas las modalidades, todas las áreas escolares, cuando yo hablaba del cuerpo docente y hablaba de esta reapropiación de los cuerpos, también hacía referencia a los cuerpos de la comunidad educativa. La ESI es un proyecto que abarca, reitero, todos los niveles, todas las modalidades. Cuando digo modalidades pienso en contextos de encierro, en educación de jóvenes y adultxs, en educación especial, educación hospitalaria, educación intercultural bilingüe, todos ellos ámbitos donde tenemos que desarrollar la ESI y donde, creo, falta mucho conocimiento. Lo contrario, y esta es una autocrítica, es el discurso único de la ESI. No puede haber un repertorio exclusivo "de la ESI" que en una escuela se repita en todas las materias. Tenemos que pensar, tenemos que construir la ESI en todas las dimensiones de la práctica educativa, en todos los niveles educativos, en todas las materias dirigidas a todos los sujetos de la 
escuela.Y, también, hay algo que tiene que ver con lo que llamamos así, muy en general y también estaría bueno seguir discutiendo, la pedagogía feminista. Porque el modo cómo se construye un proyecto de ESI no es solamente una cuestión de contenidos: también es una cuestión sobre de qué modo se construyen vínculos entre personas y, en algún sentido, contrapuesta a una persona que tiene un martillo y normativamente dice "esto está bien" o "esto está mal”. Esto también es autocrítica y crítica porque hay versiones que de alguna manera entre comillas "bajan" cómo debe ser la sexualidad correcta, cómo debe ser la sexualidad placentera y cómo hay que vivir. Una pedagogía feminista, una mirada feminista, no necesariamente sostenida por mujeres y cuerpos feminizados, es una mirada crítica sobre la histórica tríada de la pedagogía conformada por unx docente que sabe, unx estudiante que no sabe y un conocimiento que hay que pasar de un lugar a otro. La ESI también interpela a las formas pedagógicas hegemónicas.

Y, por último, la integralidad de la política implica multiplicidad de actores institucionales. Ningún proyecto vinculado con la ESI es sólo un proyecto del sistema educativo. Es un proyecto que articula diferentes áreas que tienen que ver con la justicia, con la acción social o con el desarrollo social (defensorías, salud). No puede ser que la ESI sea solo un proyecto educativo porque es insuficiente. La ESI es un proyecto social, es una política pública social que la escuela aislada no puede sostener y, además, es contraproducente que sola lo haga. Porque cada uno de ustedes, cada una de ustedes, cada une, tal vez tuvo la oportunidad de poner palabra a una situación y después no saber qué hacer con eso que sabe. Frente a una chica, un chico, una familia, una madre, un padre, que están pasando situaciones, por ejemplo, de violencia, si no contamos con una red de instituciones pensadas para acompañar y políticas públicas para reparar la vulneración de derechos, la escuela se queda con la angustia y la impotencia.

La complejidad del proyecto tiene un lema que lo resume: "Educación sexual para decidir, anticonceptivos para no abortar, aborto legal para no morir".

\section{Notas}

1. Este texto se elaboró con base en la Conferencia que dictó la Dra. Morgade en la Universidad Nacional de la Plata durante las Vo Jornadas CINIG de Estudios de Género y Feminismos y III Congreso Internacional de Identidades en 2018.

2. Puede consultarse el texto completo de la ley en: Argentina, Congreso de la Nación, Programa Nacional De Educación Sexual Integral, Ley 26.150, 2006, Recuperado de http://servicios.infoleg.gob.ar/infolegInternet/anexos/120000-124 999/121222/norma.htm

3. Dichos lineamientos están en texto completo en: Argentina, Lineamientos Curriculares para la Educación Sexual Integral, 2008, Recuperado de https://www.argentina.gob.ar/educacion/esi

4. Más detalles sobre el Plan Nacional de Prevención del Embarazo No Intencional en la Adolescencia. Recuperado de ht tps://www.argentina.gob.ar/educacion/esi/historia/embarazo-no-intencional 